\title{
Preterm Yenidoğanlarda Ağrının Azaltılmasında Etkili Bir Yöntem: Cenin Pozisyonu
}

\author{
An Effective Model of Reducing Pain in Preterm Neonates: Facilitated Tucking
}

\author{
Neriman Çağlayan*, Serap Balcı***
}

İletişim/Correspondence: Neriman ÇAĞLAYAN Adres/Adress: S.B. Okmeydanı Eğitim ve Araştırma Hastanesi, İstanbul Tel: 02123145500

E- mail: neriman-caglayan@hotmail.com

\section{$\ddot{O} Z$}

Preterm yenidoğanlar, olgunlaşmamış ağrı mekanizmaları nedeniyle yapılan girişimler sonrasında oluşan ağrıya karşı daha duyarlıdırlar. A ğrının azaltılmasında farmakolojik yöntemlerin yanında nonfarmakolojik yöntemlerinde etkili oldu$\breve{g u}$ belirtilmektedir. Bu makale; minör ağrll girişimlerde preterm yenidoğanın ă̆rısını azaltmak için kullanılan nonfarmakolojik yöntemlerden cenin pozisyonunun incelenmesi amacıyla gerçekleştirilmiştir. Konu ile ilgili yayınlar geriye dönük olarak taranmıştır. Bu amaçla İstanbul Üniversitesi internet erişsim ağl üzerinden, preterm yenidoğan (preterm newborn), ăgrl (pain), nonfarmakolojik yöntemler (nonpharmacological method), cenin pozisyonu (Facilitated Tucking) gibi anahtar kelimelerle çeşitli kombinasyonlar yapılarak Pubmed, Science Direct, Medline, Ovid arama motorlarından tarama yapılmuştır. 1995-2012 tarihleri arasında yayınlanan tüm ulusal ve uluslar arası araştırma ve derlemeler gözden geçirilmiştir. Nonfarmakolojik yöntemlerden biri olan cenin pozisyonu (Facilitated Tucking), "bebeği yuvaya alma yönteminin bir alt formu olup, bebeğin üst ve alt ekstremitelerini el ile fleksiyonda tutarak, vücudu orta hatta yakın kapalı pozisyona alma işlemi" olarak tanımlanmaktadır. Bu yöntemin ısı ve dokunsal uyarlyı sağlayarak, bebeklerin düzenleyici sistemlerini harekete geçirdiği, dış ortamdan gelen ă̆rılı uyaranları engellediği ve bebeğin duyduğu ăgrıyı azalttı̆g bildirilmektedir. Hemşireler, ağrlyı önlemek ya da azaltmak için preterm yenidoğanlarda bu yöntemi kullanabilirler.

Anahtar Kelimeler: Nonfarmakolojik yöntemler, cenin pozisyonu, preterm yenidoğan, ağrı.

\section{ABSTRACT}

Preterm newborns are more sensitive to the pain caused after such interventions, because of the matured pain mechanisms of preterms. Non-pharmacological methods are emphasized as much as pharmacological methods in reducing pain.This article was conducted to examine Facilitated Tucking which is one of the non-pharmacological methods used to reduce pain in preterm newborn. Relevant publication were screened retrospectively. This purpose; search was conducted from Istanbul University internet access across the network, search engine were used such as PubMed, Science Direct, Medline, Ovid, various combination were made keywords such as Preterm newborn, Pain, Non-Pharmacological method, Facilitated Tucking. Published between the years 1995-2012, all nation and international research and rewiev articles were reviewed.

The Facilitated Tucking, "which is one of the non-pharmacological methods, is a sub-form of the containment method and is defined as the procedure of taking the body close to the middle line in a closed position by keeping the upper and lower extremities of the baby in flexion with the hands". This method is reported to provide the heat and tactile warnings, to stimulate the regulatory systems of infant, to inhibit painful stimuli from the external environment and reduce the pain experienced by infant.

The nurses should use appropriatenon-pharmacological methods of newborn to prevention or reduction the pain. Key Words: Non-pharmacological methods, facilitated tucking, preterm newborn, pain.

*Msc. Hemşire S.B. Okmeydanı Eğitim ve Araştırma Hastanesi, **Yard.Doç. Dr.Istanbul Üniversitesi Florence Nightingale Hemşirelik Fakültesi Yazının gönderilme tarihi: 09.09.2013

Yazının basım için kabul tarihi: 17.01.2014 


\section{GíRiş}

Yenidoğan Yoğun Bakım Ünitelerinde (YYBÜ) kaldıkları süre boyunca preterm yenidoğanlar çok sayıda (günde 8- $10 \mathrm{kez}$ ) girişime maruz kalmaktadırlar (Efe 2003; Gardner, Hagedorn ve Dickey 2006; Gargiulo, Lynchve Slogar 2010). Özellikle pretermlerin, olgunlaşmamış ağrı mekanizmaları nedeniyle bu girişimler sonrası oluşan ağrıya karşı daha duyarlı oldukları belirtilmektedir (Holsti, Grunau, Whitfield, Oberlander ve Lindh 2006; Obeidat, Kahalaf, Callister ve Froelicher 2009; Prasopkittikun ve Tilokskulchai 2003). YYBÜ'lerinde uygulanan girişimler sonucunda ortaya çıkan aşırı ve uzun süreli hafifletilememiş ağrı, genellikle tüm organ ve sistemlerde hayatı tehdit edebilecek sorunlara yol açabilmektedir (Holsti, Grunau, Oberlander ve Whitfield 2004; Ludington- Hoe 2006). Bu uyaranlar sadece fizyolojik değişikliklere yol açmakla kalmazlar, ilerleyen dönemlerde nörolojik ve davranışsal bozukluklara da neden olabilirler (Huang, Tung, Kuo ve Chang 2004). Bu derlemenin amac1; minör ağrılı girişimlerde preterm yenidoğanın ağrısını azaltmak için kullanılan nonfarmakolojik yöntemlerden cenin pozisyonunun incelenmesidir.

\section{Yöntem}

Derleme, konu ile ilgili yayınların geriye dönük olarak taranması biçiminde gerçekleştirilmiştir. Bu amaçla İstanbul Üniversitesi internet erişim ağı üzerinden, preterm yenidoğan (preterm newborn), nonfarmakolojik yöntemler (non-pharmacological method), cenin pozisyonu (Facilitated Tucking) ve ağrı (pain) gibi anahtar kelimelerle çeşitli kombinasyonlar yapılarak Pubmed, Science Direct, Medline, Ovid arama motorlarından tarama yapılmıştır. 1995- 2012 tarihleri arasinda yayınlanan tüm ulusal ve uluslar arası araştırma ve derlemeler gözden geçirilmiştir.

\section{Ağrıyı Etkileyen Faktörler}

Yenidoğanın ağrıyı algılamasında ve ağrıya karşı yanıtın oluşmasında çeşitli faktörler etkilidir. Bebeğin cinsiyeti, gestasyonel haftası, sağlık durumu, doğum şekli hastalığın şiddeti, geçmiş deneyimleri, bireysel fark.l1lıkları, başetme yeteneği, uyanıklık durumu, ağrılı uyaranların tipi, süresi, uygulama zamanı, sıklığı, sağlık profesyonellerinin becerisi ve deneyimi bu faktörler arasındadır (Gardner ve ark. 2006; Ünaldı 2009; Williams, Khattak, Garza ve Lasky 2008). Ayrıca preterm yenidoğanlar termden fark.lı olarak çevresel uyaranlara daha fazla duyarlıdır. Ünitedeki ses, 1 şık ve rutin bakım girişimleri de yenidoğanların ağrıyı algılamasını ve gösterdiği tepkiyi etkilemektedir (Clifford, Stringer, Christensen ve Mountain 2004; Tar1 2003).

\section{Ağrının Etkileri}

Yenidoğanların bir kısmı ağrıya fizyolojik tepkiler gösterirken bir kısmı davranışsal yanıt verebilir. Aynı gestasyonel yaştaki yenidoğanların ağrıya tepkilerinin aynı olduğu bildirilmektedir. Term yenidoğanlar ağriya davranışsal yanıt verirken preterm yenidoğanların fizyolojik tepki gösterdiği ifade edilmektedir. Tekrarlayıcı, sık aralıklı ve uzun süren ağrı yenidoğanın tepkilerini baskılayabilmektedir (Faye ve ark. 2010; Gardner ve ark. 2006).

Yenidoğanın ağrıya verdiği yanıtlar davranışsal, fizyolojik ve hormonal olmak üzere 3 grupta toplanmaktadir (Faye ve ark. 2010; Gardner ve ark. 2006).

Yenidoğanın davranışsal ağrı tepkileri; ağlama, yüz ifadeleri, motor hareketler, davranışsal durum değişiklikleri gibi gözlemlenebilir tepkilerdir.

Yenidoğanlarda ağrının değerlendirilmesinde fizyolojik ve otonomik parametrelerden de yararlanılır. Yenidoğanda ağrı deneyimi kalp atım hızını, solunum hızın1, kan basıncını, doku oksijenlenmesini etkiler ve ağrı bu parametrelerin artmasina ya da azalmasina neden olabilir. Kalp tepe atımı (KTA) yenidoğanlarda uzamış ağrının değerlendirilmesinde kullanılan bir değişkendir (Faye ve ark. 2010). Ayrıca solukluk veya kızariklık, terleme veya palmar terleme, pupillaların dilate olması gibi değişimler de meydana gelebilir (Herrington 2007; Ludington- Hoe 2006).

Ağrılı uyarana maruz kalan yenidoğanlarda hormonal ve metabolik değişimler meydana gelmektedir. Ağriya gösterilen metabolik tepkiler; katekolaminlerin (norepinefrin ve epinefrin), glukagon, büyüme hormonu, kortizol, aldesteron ve kortikostreoidlerin salınımını artırır (Herrington 2007; Labonia 2007; Ünald1 2009) ve bu 
durum da metabolik hızın artmasına neden olur. Y1kım ürünleri olan laktat, pirüvat, ketonlar ve yağ asitlerini içeren toksinlerin dolaşımdaki sayısı artar (Herrington 2007). Hormonal ve metabolik değişim, anksiyete, hiperestezi, hiperaktivite, dikkat eksikliği ve stres bozukluklarına neden olur (Ludington- Hoe 2006). Yeterli seviyede analjezik ve anestezik madde alan yenidoğanlarda endokrin düzeylerin, toksik maddelerin dolaşımdaki düzeylerinin artmadığı, mortalite ve morbidite oranlar1nın azaldığı bildirilmiştir (Herrington 2007).

\section{Ağrıyı Azaltmada Kullanılacak Yöntemler}

Yenidoğanın ağrısını hafifletmek için kullanılan farmakolojik yöntemlerin solunum depresyonu, apne, bradikardi, hipotansiyon, desatürasyon, parsiyel hava yolu obstrüksiyonu ve hipersalivasyon gibi yan etkileri olduğu belirtilmektedir (Anand ve ark. 2003; Lago ve ark. 2009). Bunun yanında preterm yenidoğanlara invazif girişim uygulanırken sürekli olarak intravenöz (IV) morfin yükleme dozu verildiğinde bile yeterli analjezik etki sağlanamadığı ifade edilmektedir (Anand ve ark. 2003; Ludington- Hoe 2006).

Ağrıyı azaltmada farmakolojik yöntemler kadar nonfarmakolojik yöntemler üzerinde de durulmaktadır. Farmakolojik yöntemlerin, nonfarmakolojik yöntemlerle desteklenmediğinde istenilen etkiyi göstermediği saptanmıştır. Bu nedenle nonfarmakolojik yöntemler, yenidoğana uygulanan küçük invazif işlemlerde ağrı kontrolü için değerli alternatiflerdir (Johnston, Fernandes ve Campbell- Yeo 2011; Obeidat ve ark. 2009). Yenidoğanlarda sık tekrarlanan topuk kanı alma, aspirasyon gibi ağrılı işlemler sırasında uygulanan nonfarmakolojik yöntemlerin ağrıyı azaltmada etkili olduğu bulunmuştur (Johnston ve ark. 2011; Ward-Larson, Horn ve Gosnell 2004).Bu yöntemler arasında masaj, kanguru bakımı, müzik, sukroz, emzik verme, sarmalama, yuvaya alma, prone pozisyonu, sallama, annenin dokunması, anne sesi ve kokusu, emzirme ve cenin pozisyonu gibi uygulamalar sayılabilir.

\section{Cenin Pozisyonu ve Etkileri}

Cenin pozisyonu (Facilitated Tucking), "bebeği yuvaya alma yönteminin bir alt formu olup, bebeğin üst ve alt ekstremitelerini el ile fleksiyonda tutarak, vücudu orta hatta yakın kapalı pozisyona alma işlemi” olarak tanımlanmaktadır. Bu yöntem uygulanırken bebeğe lateral, supine veya prone pozisyonu verilebilir (Corff, Seideman,Venkataraman, Lutes ve Yates 1995; Hill, Engle, Jorgensen, Kralik ve Whitman2005; WardLarson ve ark. 2004). Ağrılı uygulamalarda ihtiyaca göre farklı tutma tekniklerinin kullanılabileceği bildirilmiştir. Örneğin; aspirasyon işleminde bebeğin kol ve bacaklarının vücuduna yakın tutulması tavsiye edilirken, topuk kanı alma uygulamasında bir el ile bebeğin başı tutulurken, diğeri ile bebeğin kol ve bacakları vücuduna yakın pozisyonda tutulur (Resim1-2, Cignacco ve ark. 2010).
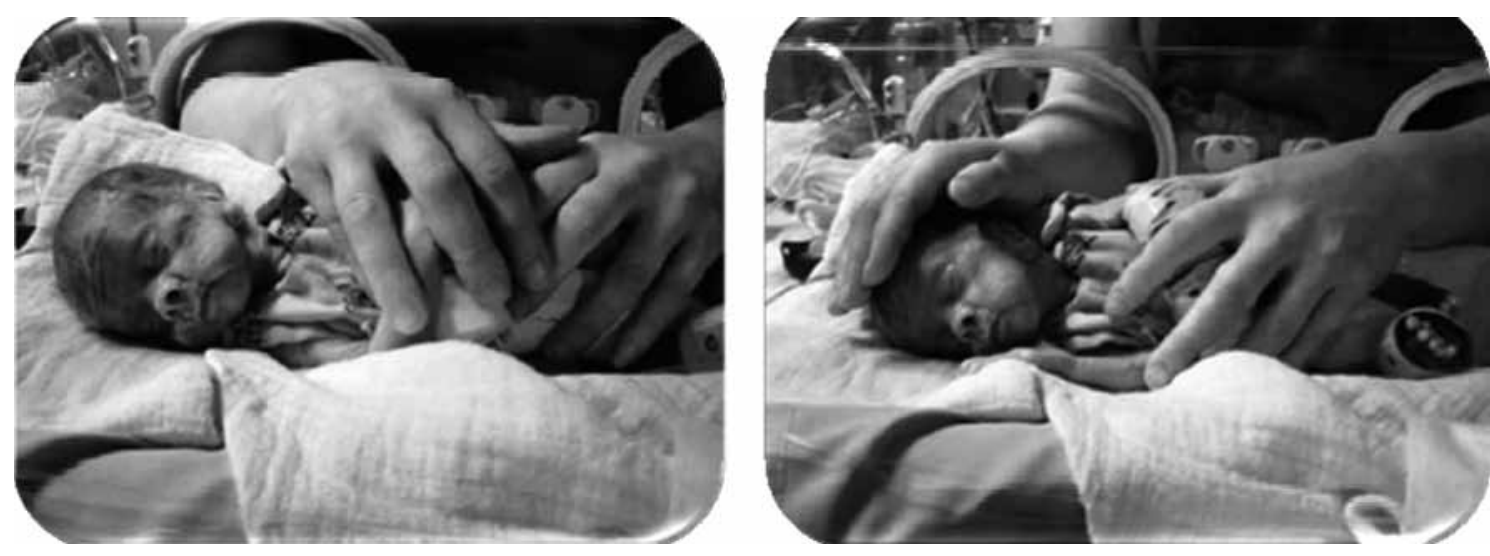

Kaynak (Resim 1 ve 2): Cignacco, E. ve ark. (2010). Facilitated tucking as a non-pharmacological intervention for neonatal pain relief: Is it clinically feasible? Acta Pcediatrica, 99: 1763-1765. 
Cenin pozisyonunun, bebeklerde 1s1 ve dokunsal uyarıyı sağlayarak, bebeklerin kendi düzenleyici sistemlerini harekete geçirdiği, bebeğin dikkatini aktifleştirdiği, dış ortamdan gelen ağrılı uyaranları engellediği, endojen endorfin salınımına yol açtığ ağrı impulslarının dağılımına yardımcı olduğu ve bebeğin duyduğu ağriyı azalttığı bildirilmektedir (Axelin, Salantera ve Lehtonen 2006; Hill ve ark. 2005). Ek olarak bebeğin uyku kalitesini geliştirdiği ve fizyolojik parametreleri de stabil hale getirdiği, pozisyona bağlı güvenlik duygusu kazanmasına, motor gelişiminin desteklenmesine ve enerjisini korumasına yardımc1 olduğu ifade edilmektedir (Herrington 2007; Obeidat ve ark. 2009). Cenin pozisyonu hem dokunsal uyarının sağladığı rahatlatıcı yönüyle, hem de bebeğin kendini koruyabileceği fizyolojik pozisyonunu almasına izin veren bir yöntem olduğu için oldukça avantajlı bir pozisyondur. Şekil 1'de cenin pozisyonunun etkileri özetlenmiştir.

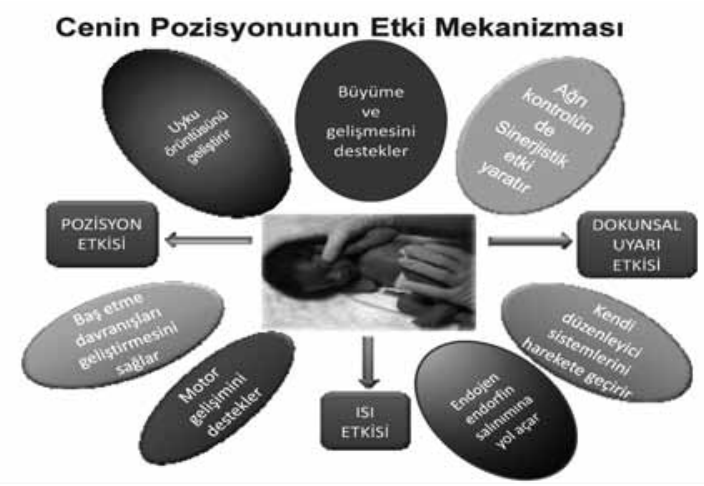

Şekil 1. Cenin Pozisyonunun Etki Mekanizması

\section{Cenin Pozisyonunun Klinik Kullanımı}

Bebeğin cenin pozisyonunda olma duygusunu hissetmesi ve ağrılı işlemle baş edebilmesi amacıyla uygulamanın $10 \mathrm{dk}$ sürdürülmesi gerektiği bildirilmektedir. Cenin pozisyonu uygulaması ağrılı işlemden $3 \mathrm{dk}$ önce başlatılıp bebeğin taktil uyarana (yetişkin eli ile tutulması) alışması ve relaksasyonu sağlanır, gevşemeyen bebeğe işlem başlatılmamalıdır. İşlem boyunca cenin pozisyonu devam ettirilir, işlem sonrası bebeğin ağrı göstergelerinin normale dönebilmesi için en az 3 $\mathrm{dk}$ cenin pozisyonunda tutulması gerekmektedir. Yöntemin uygulanabilmesi için iki hemşire gereklidir; bir hemşire bebeğe pozisyon verirken diğeri ise ağrılı girişimi uygular (Axelin ve ark. 2006; Cignacco ve ark. 2010; Obeidat ve ark. 2009).

Araştırmalarda, cenin pozisyonunun işlem sonrasındaki ağlama süresini ve ağrıyı azaltmada etkili olduğu bildirilmektedir (Axelin ve ark. 2006; Corff ve ark. 1995; Çağlayan ve Balcı 2011; Hill ve ark. 2005; Obeidat ve ark. 2009; Ward-Larson ve ark. 2004).

Corff ve ark. (1995), 25-35. gestasyonel haftadaki 30 preterm bebeği topuk kanı alma işlemi sırasında rutin (kendi aldığ pozisyon) ve cenin pozisyonunda gözlemleyerek, pozisyonun kalp tepe atımı, oksijen satürasyonu, uyku - uyanıklık durumu ve ağrı üzerindeki etkisini değerlendirmişlerdir. Cenin pozisyonunun, bebeğin ağriya karşı gösterdiği davranışsal ve fizyolojik tepkileri azaltmada etkili olduğunu bulmuşlardır. Ward- Larson ve ark. (2004), 23-32. gestasyonel haftada olan 40 entübe preterm bebekte endotrakeal aspirasyon boyunca cenin pozisyonunun ağriyı ve stresi azaltmadaki etkisini incelemişlerdir. Rutin ve cenin pozisyonundaki bebeklerin endotrekeal aspirasyon uygulanması sırasında ağrısını iki kez gözlemlemişlerdir. Bebeğin aldığı ağrı puanı PIPP (Premature Infant Pain Profile) ölçeği kullanılarak ölçülmüş ve iki pozisyonun ağrı puanları karşılaştırılarak, cenin pozisyonunun ağrıyı azaltmada sağlık bakım profesyonelleri tarafindan kolayca uygulanabilecek etkili bir yöntem olduğunu saptamışlardır.

Hill ve ark. (2005), 25-34. gestasyonel haftadaki cenin pozisyonu verilen ve verilmeyen 12 preterm yenidoğanı gözlemleyerek, pozisyonların ağrı üzerindeki etkisini incelemişlerdir. Cenin pozisyonunun ağrıyı ve stresi azaltmada oldukça başarılı bir yöntem olduğunu bildirmişlerdir.

Axelin ve ark. (2006), 24-33. gestasyonel haftadaki 20 preterm bebeğe endotrakeal/ farengeal aspirasyon işlemi sirasında ebeveyni tarafından verilen cenin pozisyonunun ağrı üzerine etkisini değerlendirmişlerdir. 
Kalp tepe atımı, oksijen satürasyonu ve NIPS ile belirlenen ağrı puan ortalamasını değerlendirerek, cenin pozisyonunun aspirasyon işlemindeki ağrıyı azaltmada etkili olduğunu vurgulamışlardır.

Huang ve ark. (2004), 25-36. gestasyonel haftadaki 30 preterm bebekten topuk kanı alma işlemi sırasında verilen cenin pozisyonu ve kundaklamanın ağrı, kalp tepe atımı ve oksijen satürasyonları üzerindeki etkisini incelemişlerdir. Kundaklama ve cenin pozisyonu arasında davranışsal ve fizyolojik stres belirtileri açısından farkın anlamlı olmasada, her iki pozisyonunda etkili olduğunu ancak cenin pozisyonundaki bebeklerin ağrı puan ortalamalarının daha düşük olduğunu belirlemişlerdir.

Herrington (2007), 27-33. gestasyonel haftadaki 20 preterm bebeği hem kendi pozisyonunda hem de cenin pozisyonu vererek ayak topuğundan kan alma işlemi sırasındaki kalp tepe atımını, solunum sayısını, oksijen satürasyonunu, ağlama süresini ve kortizol salınımını karşılaştırmıştır. Bebekler işlem öncesi, sırası ve sonrasında 2'şer dakika olmak üzere toplam 8 dakika izlenmiştir. Her iki pozisyon karşılaştırıldığında; kalp tepe atımında işlem sırası ve sonrasında anlamlı azalma varken, oksijen satürasyonu, solunum sayısı, ağlama süresi ve kortizol seviyesinde anlamlı farklılık olmadığını bulmuşlardır.

Çağlayan ve Balcı (2011), 37. gestasyonel haftanın altındaki 41 preterm yenidoğana hem rutin hem de cenin pozisyonu vererek ayak topuğundan kan alma s1rasındaki kalp tepe atımını, oksijen satürasyonu, a $\breve{g}-$ lama süresini ve ağrı puanlarını değerlendirmişlerdir. Her iki pozisyon karşılaştırıldığında; cenin pozisyonu verilen bebeklerin, rutin pozisyona göre ağrı puan ortalamalarının daha az, ağlama sürelerinin daha kısa olduğu bulunmuştur.

Cignacco ve ark. (2012), 24-32. gestasyonel haftadaki preterm yenidoğanlarda topuk kanı alma uygulamaS1 sirasinda cenin pozisyonunun ve oral sukrozun ayrı ayrı ve birlikte kullanımının ağrı üzerine etkisini değerlendirmişlerdir. Çok merkezli yapılan çalışmaya 81 preterm yenidoğan dahil edilmiştir. Sadece cenin pozisyonu verilen yenidoğanlarda oral sukroz uygulamasına göre ağrının daha fazla azaldığı, her iki yöntem birlikte uygulandığında ise ağrının daha da azaldı$\breve{g} 1$ belirtilmektedir.

\section{SONUÇ VE ÖNERÍLER}

Ağrılı girişimler sırasında preterm bebeklerin ağrısını azaltmak ve bebekleri sakinleştirmek için uygulanan cenin pozisyonu, etkili nonfarmakolojik yöntemlerden birisidir.

Hemşireler, ağrıyı önlemek ya da azaltmak için, yenidoğanın özelliklerine uygun nonfarmakolojikyöntemleri kullanmalıdırlar.Nonfarmakolojik yöntemler kliniklerde uygulanırkenuygulanabilme kolaylığı, zaman olarak uygulanabilme durumları, ekonomik ve organizasyonel faktörler göz önünde bulundurulmalıdır. Ayrıca nonfarmakolojik yöntemlerin bakımın içinde yer alması sağlanmalıdır.

Kanıta dayalı araştırmalar yoluyla yeninonfarmakolojikyöntemler takip edilmeli veuygulamaya geçirilmesi konusunda rehber olunmalıdır.

\section{KAYNAKLAR}

Anand, K. J. S. ve ark. (2003). Effects of morphine analgesia ventilated preterm neonates: Primary outcomes from the neopain randomised trial. Lancet, 363: $1673-1683$.

Axelin, A., Salantera, S., Lehtonen, L. (2006). "Facilitated tucking by parents" in pain managment of preterm infants: A randomized crossover trial. Early Human Development, 82(4): 241 -247.

Çağlayan, N., Balcı, S. (2011). Preterm yenidoğanlarda ayak topuğundan kan alma işlemi sırasında el ile verilen cenin pozisyonunun ağrı üzerine etkisi. Yayınlanmamış Yüksek Lisans Tezi, İstanbul Üniversitesi Sağlık Bilimleri Enstitüsü, İstanbul.

Cignacco, E. ve ark. (2010). Facilitated tucking as a nonpharmacological intervention for neonatal pain relief: Is it clinically feasible? Acta Pcediatrica, 99: 1763-1765.

Cignacco, E. ve ark. (2012). Oral sucrose and facilitated tucking for repeated pain relief in preterms: A randomized controlled trial. $P e$ diatrics, 129: 299-308.

Clifford, P. A., Stringer, M., Christensen, H., Mountain, D. (2004). Pain assessment and intervention for term newborns. Journal Midwifery Womens Health, 49: 514-519. 
Corff, K. E., Seideman, R., Venkataraman, P. S., Lutes, L., Yates, B. (1995). Facilitated tucking: A nonpharmacologic comfort measure for pain in preterm neonates. Journal of Obstetric, Gynecologic, Neonatal Nursing, 24: 143-147.

Efe, E. (2003). Yenidoğanlarda periferik venöz kan örneklemesi sırasındaki ağrıyı azaltmada kucakta emzirme ve emzikle sukroz solüsyonu uygulamasının karşılaştırılması. Doktora Tezi, İstanbul Üniversitesi Sağlık Bilimleri Enstitüsü, İstanbul.

Faye, M. P. ve ark. (2010). Newborn infant pain assesment using hearth rate variability analysis. Clinical Journal Pain, 00: 1-16.

Gardner, S., Hagedorn, M. I. E., Dickey, L. A. (2006). Pain and pain relief. Merenstein, B.G., Gardner, S.L. (Eds.). Handbook of Neonatal Intensive Care. Mosby Elsevier, Philadelphia.

Gargiulo, A. D., Lynch, A. M., Slogar, A. (2010). Managing heel stick pain in newborn. Journal of Obstetric, Gynecologic, Neonatal Nursing, 25: 42-46.

Herrington, C. (2007). Reducing pain of heelstick in premature infants with gentle human touch. Doctor of Philosophy, Wayne State Universty, Detroit, Michigan.

Hill, S., Engle, S., Jorgensen, J., Kralik, A., Whitman, K. (2005). Effects of facilitated tucking during routine care of infants born preterm. Pediatric Physical Therapy, 17: 158- 163.

Holsti, L., Grunau, R., Oberlander, F. T., Whitfield, M. F. (2004). Specific newborn individualized developmental care and assessment program movement are associated with acute pain in preterm infants in the neonatal intensive care unit. Pediatrics, 114(1): 65-72.

Holsti, L., Grunau, R. E., Whitfield, M. F., Oberlander, T. F., Lindh, V. (2006). Behavioral responses to pain are heightening after clustered care in preterm infants born between 30 and 32 weeks gestational age. Clinical Journal of Pain, 22: 757-764.

Huang, C., Tung, W., Kuo, L., Chang, Y. (2004). Comparision of pain responses of premature infants to the heelstick between containment and swaddling. Journal of Nursing Research, 12(1): 31-39.
Johnston, C. C., Fernandes, A. M., Campbell- Yeo, M. (2011). Pain in neonates is different. Pain, 152: 65-73.

Lago, P. ve ark. (2009). Guidelines for procedural pain in the newborn. Acta Paediatrica, 98: 932- 939.

Ludington-Hoe, S. (2006). Kangroo care for analgesia in preterm infants undergoing heel stick pain. Case Western Reserve University, Frances Payne Bolton School of Nursing, School of Graduate Studies, 1-230, http://www.ohiolink.edu/etd/send-pdf.cgi/ Ludington-Hoe\%20Xiaomei.pdf?acc_num=case 1134405075 (16.01.2010).

Prasopkittikun, T., Tilokskulchai, F. (2003). Management of pain from heel stick neonates: An analysis of research conducted in Thailand. Journal Perinatology - Neonatology Nursing, 17(4): 304-312.

Obeidat, H., Kahalaf, I., Callister, L., Froelicher, E. (2009). Use of facilitated tucking for nonpharmacological pain managment in preterm infants: A systematic review. Journal of Perinatal \& Neonatal Nursing, 23(4): 372-377.

Tarı, A. (2003). Yenidoğan yoğun bakım ünitelerinde çevrenin değerlendirilmesi ve düzenlenmesi. Pek H. (Ed.),Yenidoğan Yoğun Bakım Ünitelerinde Bireyselleştirilmiş Destekleyici Gelişimsel Bakım Kursu. Çocuk Hemşireliği Derneği, İstanbul.

Ünaldı, N. (2009). Yenidoğanlarda ağrılı işlemlerde uygulanan ötektik karışımının ve sukrozun ağrı algısına etkisi. Yüksek Lisans Tezi, Marmara Üniversitesi Sağlık Bilimleri Enstitüsü, İstanbul.

Williams, A. L., Khattak, A. Z., Garza, N. C., Lasky, R. E. (2008). The behavioural pain response to heelstick in preterm neonates studied longitudinally: description, development, determinants and components. Early Human Development, 85(6): 369- 374.

Ward-Larson, C., Horn, R., Gosnell, F. (2004). The efficacy of facilitated tucking for relieving procedural pain of endotracheal suctioning in very low birth weight infants. The American Journal of Maternal Child Nursing, 9(3): 151-158. 